\title{
BMJ Open Association of care workers' job satisfaction and global happiness with change of functional performance of severely disabled elderly residents in nursing homes: a cohort and questionnaire study in Japan
}

\author{
Shino Ikeda-Sonoda, ${ }^{1}$ Nao Ichihara (D) ${ }^{2}$ Jiro Okochi, ${ }^{3}$ Arata Takahashi, \\ Hiroaki Miyata ${ }^{1}$
}

To cite: Ikeda-Sonoda S, Ichihara N, Okochi J, et al. Association of care workers' job satisfaction and global happiness with change of functional performance of severely disabled elderly residents in nursing homes: a cohort and questionnaire study in Japan. BMJ Open 2020;10:e033937. doi:10.1136/ bmjopen-2019-033937

- Prepublication history and additional material for this paper are available online. To view these files, please visit the journal online (http://dx.doi. org/10.1136/bmjopen-2019033937).

Received 30 August 2019

Revised 01 May 2020

Accepted 01 May 2020
Check for updates

(C) Author(s) (or their employer(s)) 2020. Re-use permitted under CC BY-NC. No commercial re-use. See rights and permissions. Published by BMJ.

For numbered affiliations see end of article.

Correspondence to

Dr Nao Ichihara; nao-i@keio.jp

\section{ABSTRACT}

Objectives There is growing concern regarding quality of work life (QWL) among care staff in nursing homes. However, little is known about the impact of QWL on nursing home residents' functional performance. Recent literature suggests that job satisfaction and happiness of healthcare workers reflect their perceived QWL and impact the quality of their care. This study examined the association between job satisfaction and global happiness with change in functional performance of severely disabled elderly residents in nursing homes.

Design A retrospective cohort study of nursing home residents combined with a questionnaire survey of their care staff.

Setting Eighteen nursing homes in Japan.

Participants Data were collected from 1000 residents with a required care level of 3-5 and from 412 care staff in nursing homes between October 2017 and March 2018.

Outcomes and explanatory variables Functional performance was structurally assessed with ICF (International Classification of Functioning, Disability and Health) staging, composed of 52 items concerning activities of daily life, cognitive function and social participation, at baseline and 6 months later. Deterioration and improvement of functional performance were dichotomously defined as such change in any of the items. QWL of care staff was evaluated with a questionnaire including questions about job satisfaction and global happiness.

Results Functional performance deteriorated and improved in $23.0 \%$ and $12.7 \%$ of residents, respectively. Global happiness of care staff was associated with lower probability of residents' deterioration (adjusted $\mathrm{OR}, 0.61$; $\mathrm{Cl} 0.44$ to 0.84 ). There was no significant correlation between job satisfaction or happiness of care staff and improvement of residents' functional performance. Conclusion These results suggest that QWL of care staff is associated with changes in functional performance of elderly people with severe disabilities in nursing homes.
Strengths and limitations of this study

- This is the first study to investigate the correlation between quality of work life, specifically job satisfaction and global happiness, of care staff and changes in functional performance of elderly people with severe disabilities in nursing homes.

- Data included functional performance assessments of 1000 residents at 18 nursing homes across Japan at two time points at an interval of 6 months (retrospective cohort study) and the perceptions of 412 care staff at these nursing homes (questionnaire survey).

- Residents' functional performance was structurally recorded using ICF (International Classification of Functioning, Disability and Health) Staging, a standardised and validated instrument that enables holistic, reproducible assessment of a person's functional status, including activities of daily living, cognitive function and social participation, without the need for extensive training of users.

- The 6-month observation period of this study was relatively short for capturing functional changes of residents and necessitated aggregating multifaceted functional performance changes into binary indicators of deterioration and improvement.

\section{INTRODUCTION}

In developed nations, population ageing and increased life expectancy have resulted in increased demand for elderly care and a shortage of care workers. ${ }^{12}$

\section{Care worker shortage in Japan}

In Japan, as the number of elderly people requiring nursing care increases, so does the need for a large number of care workers. A care worker is defined as a person who provides direct care in long-term care settings, 
including nursing homes, and they compose $41.3 \%$ of the workers in the long-term care settings; $62.6 \%$ of the care workers work full time and $60.7 \%$ of them have been licensed as certified care workers, a national qualification which is granted by the government, but not legally required in care worker jobs. ${ }^{3}{ }^{4}$ The Japanese government has estimated that by year 2025 , it will be necessary to secure an additional care workforce of 550000 while assuring the quality of care and containing costs; nursing homes have experienced a serious shortage of care workers. ${ }^{5}$ The effective ratio of job vacancies to job applicants for care worker was more than 3.95 across the nation in $2018 .{ }^{56}$ There are long waiting lists for special nursing homes, partly due to labour shortage. ${ }^{7}$ Therefore, the government and administrators of nursing homes and service providers must determine how to maintain and improve work environments to recruit and retain care workers.

\section{Quality of work life}

There is growing concern regarding the impact of quality of work life (QWL) perceived by care staff on the quality of care in nursing homes. ${ }^{8-10} \mathrm{QWL}$ is an umbrella concept that encompasses a wide range of work-related issues. ${ }^{10}$ Some studies have considered QWL as a broad set of beneficial outcomes of working life. ${ }^{11}$ Other studies have described QWL as the quality of interaction between individuals and every dimension of work. ${ }^{11}$ In some previous studies, perceived QWL was assessed using job satisfaction and global happiness. ${ }^{10} 12$

There are a number of reports on factors that affect job satisfaction of healthcare workers. A previous study in nursing homes showed that internal factors which affect job satisfaction about perceived job characteristics are supervisor support, workload, financial rewards, career rewards, quality of coworkers, perceived quality of care and team care. The same study showed that external factors with such impact are contingency factors (eg, being a primary breadwinner), personal characteristics (eg, age, sex), organisational factors (eg, type of ownership) and economic factors. ${ }^{13}$ Other studies revealed that job satisfaction among those who provide direct resident care in residential long-term care facilities is influenced by empowerment and autonomy as individual factors, and by facility resources and workload as organisational factors. ${ }^{71415}$ Some other studies of QWL in healthcare settings have focused on global happiness. ${ }^{12}$ Global happiness is traditionally and often measured with a simple item: 'Taking all things together, would you say you are ...: very happy, quite happy, not very happy, or not at all happy'. ${ }^{17}$ A further development of the global happiness scale, the 'Subjective Happiness Scale', developed by Lyubomirsky and Lepper, ${ }^{18}$ consists of four items and has become commonly used to measure global happiness. ${ }^{1718}$ Healthcare workers' happiness can be attributed to a number of personal factors and job environment characteristics. ${ }^{19}$ Personal factors, such as physical exhaustion and anxiety, negatively affect the global happiness of healthcare workers. ${ }^{20-22}$ Organisational/context-related factors, such as job tasks, relationships with colleagues and superiors, and lack of safety, also impact the global happiness of healthcare workers. ${ }^{22-25}$

Previous studies have illustrated that job satisfaction and global happiness affect the quality of care provided by care staff through job commitment. ${ }^{26}$ Care communities with highly committed staff members endeavour to integrate the wishes, preferences and care needs of residents by respecting their privacy, dignity, comfort and choice in various activities. ${ }^{27}$ Similarly, committed care workers are more likely to respond to residents' health changes through appropriate communication among care communities. $^{27}$

It has been reported that job satisfaction of long-term care staff is correlated with health-related outcomes of the residents. Higher job satisfaction of care staff in nursing homes is associated with lower rates of resident injuries and residents' higher satisfaction and wellbeing. ${ }^{26}{ }^{28}$ Higher job satisfaction and global happiness of care managers are associated with clients' higher satisfaction and happiness with care. ${ }^{12}$ However, little is known regarding the association between QWL-related concepts, specifically job satisfaction and global happiness, and functional performance of elderly people with severe disabilities.

\section{Functional performance of elderly people with severe disabilities}

The degree of disability and dependency varies among elderly people who live in nursing homes. ${ }^{29}$ It is expected that elderly people with different degrees of disability and dependency have different tendencies of deterioration or improvement in their functional performance. Also, it is reasonably assumed that people with different degrees of disability and dependency have their functional performance affected by different factors. However, very few studies have focused on care outcomes of the elderly people with severe disabilities.

\section{Long-term care insurance system in Japan}

In Japan, elderly people with disabilities are eligible to receive long-term care under the public long-term care insurance (LTCI) system. ${ }^{30}$ There are various types of residential care facilities for the elderly, including LTCI facilities such as special nursing homes, geriatric health facilities, sanatoria or integrated facilities for medical and long-term care. Elderly people who need care are stratified by the degree of disability and dependency and certified as requiring a care level from 1 (mild) to 5 (severe). ${ }^{31}$ Those with moderate to severe disabilities, or a required care level of 3-5, are allowed to reside in special nursing homes which are specifically designed to address their needs. Typically, a person with a required care level of 3 (moderate) needs full assistance for standing, walking, dining, toileting and bathing. A typical person with a required care level of 5 (severe) needs full assistance for most essential activities for survival, for example, nutrition 
Conceptual model of correlation between care staff's QWL and residents' functional performance

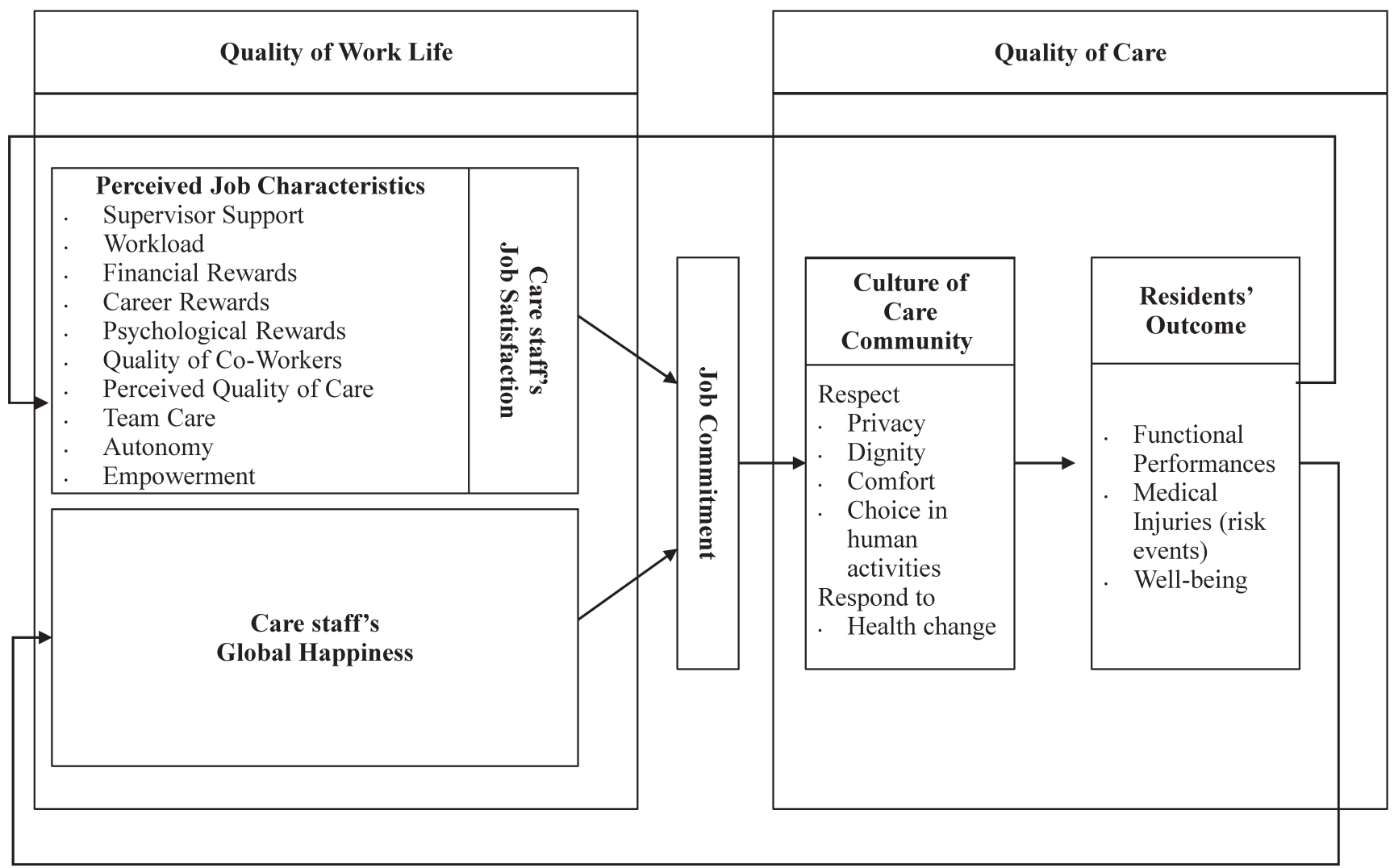

Figure 1 Conceptual model of correlation between care staff's quality of work life and residents' functional performance. We hypothesised that care staff's job satisfaction and global happiness affect the quality of care through job commitment, and job commitment affects culture of care in the facility and affects functional performance.

intake, excretion, maintenance of skin condition and avoidance of pressure ulcers, with a limited ability to comprehend their surroundings and communicate with others.

\section{Aim of this study}

The aim of this study was to examine how job satisfaction and global happiness of care staff were correlated with changes in functional performance of elderly people with severe disabilities in Japanese special nursing homes.

A conceptual model of the correlation between care staff's QWL and functional performance of residents in nursing homes is shown in figure 1.

\section{METHODS}

\section{Study design}

This was a retrospective cohort study of residents of special nursing homes, combined with a questionnaire survey with care staff at the nursing homes.

\section{Participants and settings}

The residents and care staff of the nursing homes that agreed to cooperate were invited to participate in the study. Written consent to participate in the study was obtained from each resident, or his or her proxy family member if the resident had cognitive impairment and was deemed by the care manager to be unable to give informed consent. Consent from staff was obtained through the software described below. They were informed that they could withdraw at any time and that all information related to them would remain confidential. Data were anonymised at the nursing homes and sent to the investigators. Only residents with a required care level of 3,4 or 5 were included in the study, as required care levels 3, 4 and 5 represent moderate to severe disability typical for residents in special nursing homes.

For efficient and accurate data collection, nursing homes which have a specific information system called 'CAREKARTE' implemented were asked to participate in the study. CAREKARTE was developed by Fuji Data System, Japan, and integrates functionalities for care recording and operational management.

\section{Measures}

Outcome variables (functional performance): ICF Staging

Concerning functional performances of elderly people, it is widely accepted that maintaining independence in activities of daily living (ADL) and cognitive functions and engaging in society are critical for people's quality of life as they age. ${ }^{32-34}$

In this study, functional performance of the residents was measured using the ICF (International Classification 
Table 1 Functional performance domains and categories in the ICF Staging

$\begin{array}{ll}\text { Activities of } & \text { 1. Basic posture control. } \\ \text { daily living } & \text { 2. Walking and moving function. } \\ & \text { 3. Eating function: swallowing. } \\ & \text { 4. Eating function: feeding and feeding } \\ \text { assistance. } & \text { 5. Toileting function. } \\ & \text { 6. Bathing function. } \\ & \text { 7. Personal care function: oral care. } \\ \text { 8. Personal care function: self-care. } & \text { 9. Orientation. } \\ \text { function } & \text { 10. Communication. } \\ \text { Social } & \text { 11. Mental activities. } \\ \text { participation } & \text { 12. Leisure. }\end{array}$

ICF, International Classification of Functioning, Disability and Health.

of Functioning, Disability and Health) Staging. ICF Staging is an instrument developed by the Japan Association of Geriatric Health Service Facilities used to evaluate the functional performance of elderly people and is structured in line with the WHO ICF codes. ${ }^{35}$ Table 1 shows the 13 categories of the ICF Staging items in the domains of ADL, cognitive function and social participation, each of which consists of four questions corresponding to an ICF code, comprising 52 items in total. ${ }^{36}$ The ICF Staging facilitates objective and multifaceted descriptions of elderly functional performance efficiently and without the need for extensive training. ${ }^{37}$

ICF Staging is regularly used in more than 1000 Japanese intermediate facilities and nursing homes. ${ }^{35}$ Previous studies have revealed this instrument has high validity, test-retest reliability and sensitivity to change. ${ }^{37-40}$

\section{Explanatory variable 1: care staff's QWL survey}

Care staff's QWL survey included six items: job satisfaction, global happiness, psychological rewards, intention to leave and perceived quality of care at the facility (two items). Global happiness was scored on a scale of $0-10$, with 0 representing 'not happy at all' and 10 representing 'very happy'. Job satisfaction and psychological rewards items ('To what extent are you satisfied with your work?' and 'How psychologically rewarding is your work?') were scored on a scale of $1-6$, with 1 representing 'not at all' and 6 representing 'extremely'. Frequency of intentions to leave from the current care facilities was scored on a scale of 1-4, where 1 represented 'often' and 4 represented 'not at all'. Items addressing perceived quality of care at the facility ('To what extent are you satisfied with the quality of care provided at the nursing home at which you work?' and 'To what extent would you recommend the nursing home at which you work to your family and friends?') were scored on a scale of $1-5$, where 1 represented 'not at all' and 5 represented 'extremely'.

Previous studies have shown that career rewards, intentions to leave and perceived quality of care are elements composing staff job satisfaction. ${ }^{14}{ }^{41}{ }^{42}$ In this study, we assumed that job satisfaction and global happiness represent major aspects of QWL of care staff in nursing homes, and chose these two factors as explanatory variables in the analysis of this study.

\section{Explanatory variable 2: risk events}

As risk events, falls, new pressure ulcers, aspiration pneumonia and fever were recorded. ${ }^{28}$

\section{Procedure}

All data were collected from October 2017 through March 2018. Residents' age, sex and required care levels were obtained from the care records.

Residents' functional performance was assessed by the care managers and recorded in the aforementioned software at an interval of 6 months. The data on a resident were compared between time points and evaluated either as improved, deteriorated or no change. In this study, the primary outcome measure was change, either deterioration or improvement, in any of the 52 ICF Staging items. Note that improvement and deterioration might coexist within an individual.

Occurrence of undesirable risk events within the same 6 months was also reported by the care managers through review of the care record.

An electronic survey with care staff on their perceived QWL was also conducted at the end of the 6-month period. Responses to each item on the questionnaire were summarised as follows to create a facility-level binary indicator. First, the response of each care staff member was recoded either as 'high' (equal to or above a prespecified threshold) or 'low' (below the threshold). The threshold for job satisfaction, on a scale of 1-6, was 4 and that for global happiness, answered on a scale of $0-10$, was 5 . Second, responses within each facility were summarised either as 'high proportion' (proportion of 'high' responses equal to or above the median across facilities) or 'low proportion' (proportion of 'high' responses below the median across facilities).

\section{Resident and public involvement}

Nursing home residents and care staff were not directly involved in the design and conduct of this research; however, the authors have a constant relationship with residents, care workers and managers of nursing homes. Their insights have been incorporated into the design of this study through informal interviews with the administrators and care managers of participating facilities. The authors plan to formally invite nursing home residents and care staff to determine optimal strategy for disseminating the results of this study.

\section{Statistical analyses}

Survey responses of care staff at each facility were converted to facility-level binary indicators, as described earlier, and 


\section{Study cohort}

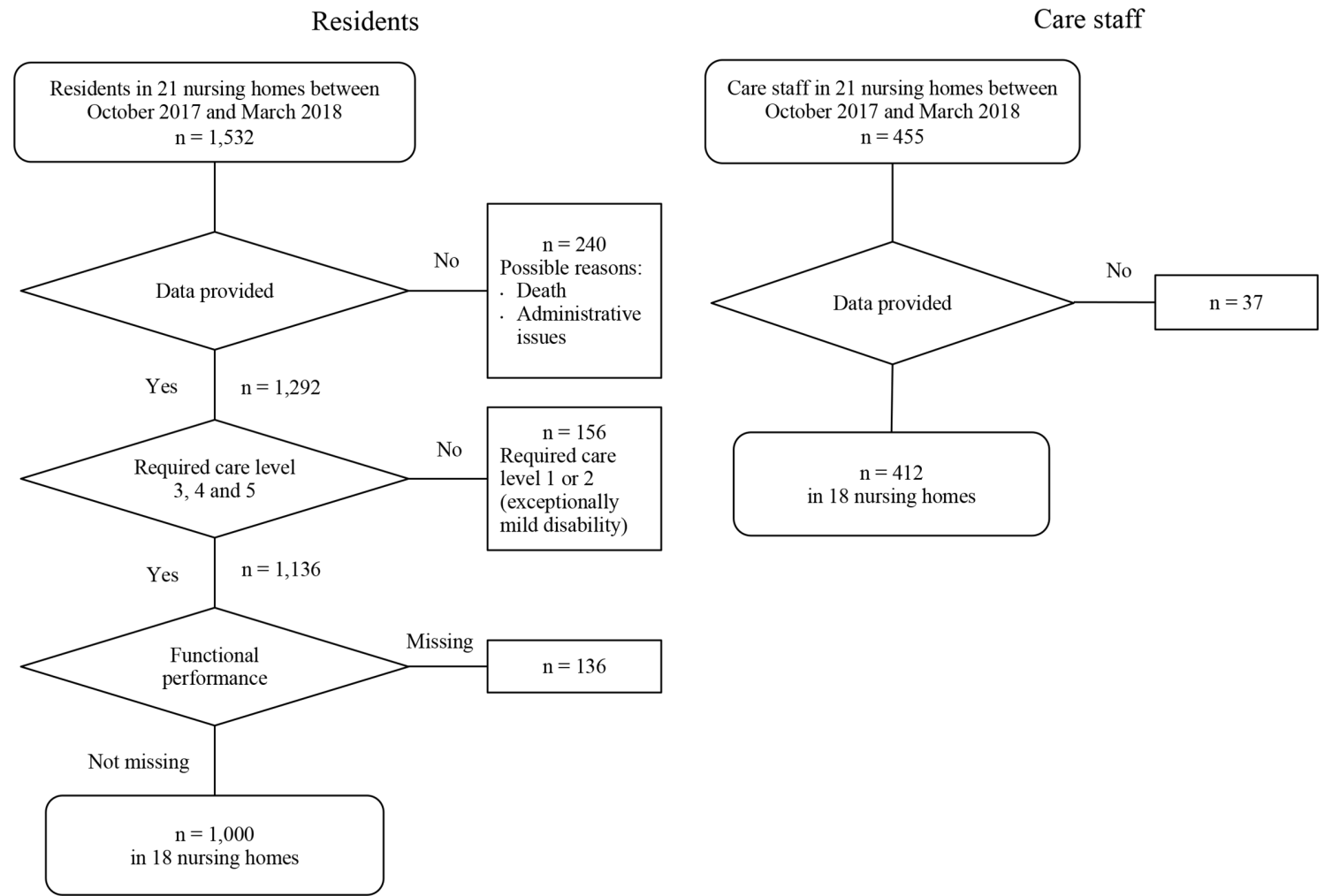

Figure 2 Study cohort. A total of 1532 residents and 455 care workers from 21 special nursing homes participated in this study. The analysis cohort included 1000 residents with 412 corresponding care workers from 18 special nursing homes.

combined with the resident data. All analyses, except when indicated, were conducted in a unit of residents.

Correlation of deterioration and improvement of functional performance with resident features, risk events and job satisfaction and global happiness of care staff was assessed using Pearson's $\chi^{2}$ test.

Multivariable logistic regression was used to estimate effects of care staff's job satisfaction and global happiness on change in functional performance adjusted for other covariates. Age, sex, required care level, risk events and job satisfaction and global happiness of care staff were included in the model.

Analysis of distribution of variables, analysis of bivariate correlations and the multivariable logistic regression were all conducted with and without stratification with required care level. Statistical analysis was performed using JMP computer software (JMP Pro V.14.3, SAS Institute, USA). A p value less than 0.05 was considered statistically significant.

The Strengthening the Reporting of Observational Studies in Epidemiology cohort reporting guidelines were used. ${ }^{43}$

\section{RESULTS}

\section{Resident characteristics, staff responses and risk events}

A total of 1532 residents and 455 care workers from 21 special nursing homes participated in this study (figure 2). The data of 1292 residents were collected.
While the reason for missing data at this stage is unclear, it may be attributed to either the death of certain residents or administrative issues. Residents with required care levels of 3, 4 and $5(\mathrm{n}=1136)$ were included in the analysis. We excluded the data of residents with missing functional performance data or care worker responses. As a result, 1000 residents with 412 corresponding care workers from 18 special nursing homes were included in the analysis. The proportion of missing values was $3.1 \%$ for items on residents' functional performance and $1.2 \%$ for items on the QWL of care staff.

The proportions of residents with required care levels of 3,4 and 5 are $23.9 \%, 39.5 \%$ and $36.6 \%$, respectively (table 2). Most residents (80.6\%) were female and more than half of the residents were aged 85-94. Baseline functional performance is summarised in online supplementary table 1.

Online supplementary table 2 summarises the care staff's responses. The median and IQR of job satisfaction were 4 (4-5) out of 6 and those of global happiness were 7 (6-8) out of 10 . Online supplementary table 3 indicates the distribution of the care staff's job satisfaction and global happiness summarised in the unit of residents.

As shown in online supplementary table 4 , the most common undesirable risk events among residents in the 6 -month period of observation were fever $(18.3 \%)$ and falls $(15.6 \%)$. 
Table 2 Sex and age of nursing home residents

\begin{tabular}{|c|c|c|c|c|}
\hline $\begin{array}{l}\text { Baseline } \\
\text { characteristics }\end{array}$ & $\begin{array}{l}\text { Required care level } 3 \\
(\%) \\
(n=239,23.9 \%)\end{array}$ & $\begin{array}{l}\text { Required care level } 4 \\
(\%) \\
(n=395,39.5 \%)\end{array}$ & $\begin{array}{l}\text { Required care level } 5 \\
(\%) \\
(n=366,36.6 \%)\end{array}$ & $\begin{array}{l}\text { Total }(\%) \\
(n=1000)\end{array}$ \\
\hline \multicolumn{5}{|l|}{ Sex } \\
\hline Female & 78.2 & 79.7 & 83.1 & 80.6 \\
\hline Male & 21.8 & 20.3 & 16.9 & 19.4 \\
\hline \multicolumn{5}{|c|}{ Age groups, in years } \\
\hline $80-84$ & 14.6 & 13.7 & 18.6 & 15.7 \\
\hline $85-89$ & 28.9 & 27.8 & 27.9 & 28.1 \\
\hline $90-94$ & 33.1 & 22.3 & 21.3 & 24.5 \\
\hline $95+$ & 10.9 & 16.7 & 13.1 & 14.0 \\
\hline
\end{tabular}

\section{Change in functional performance}

As shown in tables 3A,B, $23.0 \%$ of the residents exhibited deterioration while $12.7 \%$ exhibited improvement, both in any of the functional performance items. The overlap between deterioration and improvement of functional performance is displayed in online supplementary table 5. Regarding ADL, both deterioration and improvement were more frequent in residents with lower required care levels. Cognitive function more frequently deteriorated and less frequently improved in residents with higher required care levels. Social participation rarely improved in residents with the required care level of 5 . As the proportion of change was highest in ADL, the residents' 'overall' deterioration and improvement most reflected that in ADL.

\section{Bivariate correlation and multivariable logistic regression analyses}

The correlation of change in residents' functional performance with care staff job satisfaction and global happiness is presented in online supplementary tables $4 \mathrm{~A}$ and $5 \mathrm{~A}$ for unadjusted $\mathrm{OR}$ and online supplementary tables $4 \mathrm{~B}$ and 5B for adjusted OR. Similarly, the correlation of change in functional performance with resident features and risk events is presented in online supplementary tables $6 \mathrm{a}$ and 7 a for unadjusted OR and online supplementary tables $6 \mathrm{~b}$ and $7 \mathrm{~b}$ for adjusted OR.

The correlation of change in the subdomains of functional status (ie, ADL, cognitive function and social participation) with care staff job satisfaction and happiness is summarised in online supplementary tables $8 \mathrm{a}$,b.

Online supplementary table 9 summarises the results of the bivariate correlation analysis and the multivariable logistic regression analysis.

\section{Correlation between care staff's QWL and residents' deterioration}

As in tables $4 \mathrm{~A}, \mathrm{~B}$, the residents of facilities with a high proportion of happy care staff were less likely to deteriorate. The results are similar between bivariate correlation

Table 3 Proportion of residents with deterioration and improvement

\begin{tabular}{|c|c|c|c|c|}
\hline & $\begin{array}{l}\text { Required care level } 3 \\
(\%) \\
(n=239,23.9 \%)\end{array}$ & $\begin{array}{l}\text { Required care level } 4 \\
(\%) \\
(n=395,39.5 \%)\end{array}$ & $\begin{array}{l}\text { Required care level } 5 \\
(\%) \\
(n=366,36.6 \%)\end{array}$ & $\begin{array}{l}\text { Total }(\%) \\
(n=1000,100.0 \%)\end{array}$ \\
\hline \multicolumn{5}{|l|}{ (A) Deterioration } \\
\hline ADL & 17.6 & 17.5 & 13.4 & 16.0 \\
\hline Cognitive function & 5.0 & 6.1 & 8.2 & 6.6 \\
\hline Social participation & 6.3 & 6.6 & 5.2 & 6.0 \\
\hline Total & 27.6 & 22.8 & 20.2 & 23.0 \\
\hline \multicolumn{5}{|l|}{ (B) Improvement } \\
\hline ADL & 11.7 & 6.6 & 5.7 & 7.5 \\
\hline Cognitive function & 7.1 & 3.3 & 2.7 & 4.0 \\
\hline Social participation & 4.2 & 4.1 & 0.8 & 2.9 \\
\hline Total & 19.7 & 12.2 & 8.7 & 12.7 \\
\hline
\end{tabular}

Proportion of residents with deterioration and improvement in any of the 52 items of the functional performance assessment tool (ICF Staging).

ADL, activities of daily living; ICF, International Classification of Functioning, Disability and Health. 
Table 4A Correlation of deterioration in functional performance with care staff job satisfaction and global happiness

\begin{tabular}{|c|c|c|c|c|}
\hline & Required Care Level 3 & Required Care Level 4 & Required Care Level 5 & Total \\
\hline & ( $n=239$ to $23.9 \%)$ & $(n=395$ to $39.5 \%)$ & $(n=366$ to $36.6 \%)$ & $(n=1000)$ \\
\hline Job satisfaction & $1.14(0.64-2.00)$ & $0.83(0.52-1.33)$ & $0.79(0.48-1.32)$ & $0.88(0.66-1.18)$ \\
\hline
\end{tabular}

Unadjusted OR obtained through bivariate correlation analysis with their $95 \% \mathrm{Cls}$. ORs of resident features and risk events are presented in online supplementary table $6 a$.

A $p$ value less than 0.05 was considered statistically significant and marked bold.

analysis (unadjusted OR: 0.73 CI 0.54 to 0.98 ; table 4A) and multivariable regression analysis (adjusted OR: 0.61, CI 0.44 to 0.84 ; table $4 \mathrm{~B}$ ).

When stratified by required care levels, the same trend was observed throughout, with a statistically significant difference observed in required care level 4 . The results are similar between bivariate correlation analysis (unadjusted OR in required care level 4: 0.50 , CI 0.31 to 0.81 ; table $4 \mathrm{~A}$ ) and multivariable regression analysis (adjusted OR in required care level 4: 0.36, CI 0.21 to 0.64 ; table 4B).

Job satisfaction and happiness are represented by facility-level binary indicators ( 1 if the proportion of the above-threshold responses is equal to or above the acrossfacilities median and 0 if it is below the median).

The adjusted ORs of resident features and risk events are presented in online supplementary appendix table $6 b$.

\section{Correlation between care staff's QWL and residents' improvement}

As shown in tables 5A,B, in the entire cohort, no significant correlation was found between improvement of residents' functional status and care staff job satisfaction or global happiness.

In analyses stratified by required care level, correlation was observed between chance of improvement and care staff job satisfaction in required care level 4. Similar results were found in both bivariate correlation analysis (unadjusted OR in required care level 4: 2.56, CI 1.33 to 4.93; table 5A) and multivariable logistic regression analysis (adjusted OR in required care level 4: 2.84, CI 1.36 to 5.93; table 5B).

Job satisfaction and happiness are represented by facility-level binary indicators ( 1 if the proportion of the above-threshold responses is equal to or above the acrossfacilities median and 0 if it is below the median).
The adjusted ORs of resident features and risk events are presented in online supplementary table $7 \mathrm{~b}$.

\section{DISCUSSION}

This is the first study, to our knowledge, to examine the association between changes in residents' functional performance and the job satisfaction and happiness of care staff in nursing homes. The residents in nursing homes with high proportion of happy care staff had a statistically lower chance of deterioration. The authors believe that similar association may exist in other settings in long-term care for the elderly.

The observed correlation between staff happiness and residents' functional deterioration theoretically implies that, as described in the Introduction section, happy staff tend to highly commit to their job. Organisational culture may change in their nursing home, which promotes maintenance of residents' functional performance through provision of adequate communication and high-quality care. $^{26}{ }^{27} 44-46$ Also, either high-quality care leading to residents' favourable outcomes, or residents' functional performance itself being maintained or improved, might in turn promote the happiness of care staff through professional fulfilment. ${ }^{47}$

The results here are not robust, possibly due to a limited number of observations for examining this correlation. In subgroup analyses on residents with each required care level, statistically significant differences were observed only in residents with a required care level of 4. A possible explanation is that, in general, many of the residents with a required care level of 3 have health problems which are still not completely stable and exercise a major influence on their functional performance outcome, and residents with a required care level of 5

Table 4B Multivariable logistic regression analysis of deterioration in residents' functional performance

\begin{tabular}{|c|c|c|c|c|}
\hline & Required care level 3 & Required care level 4 & Required care level 5 & Total \\
\hline & $(n=239,23.9 \%)$ & $(n=395,39.5 \%)$ & $(n=366,36.6 \%)$ & $(n=1000)$ \\
\hline Job satisfaction & 1.71 (0.90 to 3.26$)$ & 1.18 (0.70 to 2.00$)$ & 0.92 (0.53 to 1.59$)$ & 1.07 (0.79 to 1.47$)$ \\
\hline
\end{tabular}

Adjusted ORs obtained through multivariable logistic regression analysis with their $95 \% \mathrm{Cls}$.

A $p$ value less than 0.05 was considered statistically significant and marked bold. 
Table 5A Correlation of improvement in functional performance with care staff job satisfaction and global happiness

\begin{tabular}{|c|c|c|c|c|}
\hline & Required care level 3 & Required care level 4 & Required care level 5 & Total \\
\hline & $(n=239,23.9 \%)$ & $(n=395,39.5 \%)$ & $(n=366,36.6 \%)$ & $(n=1000)$ \\
\hline Job satisfaction & 0.55 (0.29 to 1.07$)$ & 2.56 (1.33 to 4.93$)$ & 0.80 (0.39 to 1.66$)$ & $1.06(0.73$ to 1.54$)$ \\
\hline
\end{tabular}

Unadjusted ORs obtained through bivariate correlation analysis with their $95 \% \mathrm{Cls}$. ORs of resident features and risk events are presented in online supplementary table $7 \mathrm{a}$.

A p value less than 0.05 was considered statistically significant and marked bold.

may tend to be irreversibly disabled with static diseases. Observation of a larger number of residents would allow for more reliable statistical analysis. Alternatively, a study design with a stronger focus on residents whose functional performance can theoretically be influenced by quality of care, such as excluding bedridden residents and those who have just been discharged from a hospital, may make it possible to more efficiently examine the correlation under discussion.

The results of this study imply that improvement of care staff's working environment might lead to higher quality of care and in turn maintenance or improvement of the functional performance in residents of certain severity levels. ${ }^{76-28} 414448$

The working environment of care staff in nursing homes has specific issues that could be improved with organisational efforts. Relationships with other staff members and a poor career outlook have been reported to be among the major causes of care staff turnover in Japan. ${ }^{5}$ Changing these QWL-related factors may improve staff perceptions of the QWL, which may promote their commitment to their job. It will lead to cultural change and hence improved quality of care provided in nursing homes. The authors believe that evaluation of effectiveness of such an approach deserves further study.

The authors also envision an alternative approach to improving functional outcome of residents in nursing homes, which is to educate the care staff on physical, psychological and social process of ageing and dying, as well as grief of the family of residents and care staff themselves. Training on how to cope with ageing and dying should also be provided. We believe such education and training might mitigate the psychological stress associated with working with residents with severe disabilities and prevent compassion fatigue. ${ }^{49-53}$
Care staff in nursing homes must regularly cope with residents' functional decline, burdens associated with the terminal stage of life, and death. ${ }^{49}$ In palliative and intensive care settings, compassion fatigue is reported to be a serious cause of nurse burn-out. ${ }^{504-58}$ There are reports of compassion fatigue of family members of elderly people with severe disabilities. ${ }^{515960}$ Compassion fatigue may also impact care staff in nursing homes. ${ }^{52} 53$ Organisational programmes for preventing compassion fatigue may help care staff in nursing homes maintain their own psychological health. ${ }^{61}$ The effectiveness of such an approach remains an open question requiring further study.

\section{Limitations}

In this study, only the perceptions of nursing home care staff were used to assess their QWL. More detailed and objective factors should be combined to assess QWL in nursing homes in future studies.

In addition, many of this study's participants were relatively stable, and even within the observation period of 6 months only a small portion of them exhibited change according to the ICF Staging. Although Mitnitski $e t a l^{62}$ insisted a frailty index should be defined as the proportion of accumulated deficits, we labelled an elderly person as exhibiting change if any of the items measured showed improvement or deterioration. Some participants exhibited improvement and deterioration concurrently.

Even though functional performance was assessed with a validated instrument, the assessment may have been affected by inter-rater variation. Measurement of walking ability and muscle strength, and more formal assessment of cognitive function, would increase the objectivity of functional performance assessment and allow more reliable conclusions to be drawn regarding the correlation

Table 5B Multivariable logistic regression analysis of improvement in residents' functional performance

\begin{tabular}{|c|c|c|c|c|}
\hline & Required care level 3 & Required care level 4 & Required care level 5 & Total \\
\hline & $(n=239,23.9 \%)$ & $(n=395,39.5 \%)$ & $(n=366,36.6 \%)$ & $(n=1000)$ \\
\hline Job satisfaction & 0.73 (0.36 to 1.50$)$ & 2.84 (1.36 to 5.93$)$ & 0.92 (0.43 to 1.97$)$ & $1.14(0.76$ to 1.69$)$ \\
\hline
\end{tabular}

Adjusted ORs obtained through multivariable logistic regression analysis with their $95 \% \mathrm{Cls}$.

A p value less than 0.05 was considered statistically significant and marked bold. 
between QWL of care staff and residents' functional performance. ${ }^{63}$

This study was conducted in Japanese special nursing homes and the target group was elderly people with moderate to severe disabilities. Expanding the target group to the elderly with mild disabilities or in different facilities and home care situations would help foster deeper understanding of the association between the QWL of care workers and changes in functional performance of elderly people.

\section{CONCLUSIONS}

The present study assessed how changes in residents' functional performance are related to job satisfaction and happiness of care staff in nursing homes. Nursing home residents with a higher proportion of happy care staff had a lower chance of deterioration. Detailed observations of the care process are needed to obtain further insight into the interaction between the happiness of care staff and residents' functional performance. Although the detailed mechanisms are unknown, the results of this study imply that long-term care for the elderly with severe disabilities could be improved by directing attention to both the QWL of care staff and the functional performance of residents, ideally creating a virtuous cycle.

\section{Author affiliations}

${ }^{1}$ Department of Health Policy and Management, Keio University School of Medicine Graduate School of Medicine, Shinjuku-ku, Tokyo, Japan

${ }^{2}$ Department of Healthcare Quality Assessment, The University of Tokyo, Bunkyo-ku, Tokyo, Japan

${ }^{3}$ Geriatric Health Services Facility of Tatsumanosato, Wakakoukai Health Care Corporation, Daito City, Osaka, Japan

AcknowledgmentsWe would like to thank our Advisory Group including Toru Takebayashi and Tomonori Okamura. We are also grateful to the participating administrators, care staff and residents of nursing homes, and Ken Ishikawa, the former head of the Japanese Council of Senior Citizens Welfare Service, who made this study possible. Finally, we acknowledge the contributions of Satoru Yoshie and Takanori Fujita, who helped in the early stages of the project.

Contributors SI-S planned and designed the research, collected and analysed the data, and drafted and revised the manuscript and its accompanying materials. NI provided advice on study design, data collection and data analysis, revised the manuscript and its accompanying materials, and approved them for submission. J0 provided advice on study design based on domain knowledge and expertise in research on long-term care. AT provided support in summarising the data. HM provided administrative support and general advice.

Funding This work was supported by the Japanese Council of Senior Citizens Welfare Service Thinktank (JS) in 2017.

Competing interests None declared.

Patient consent for publication Not required.

Ethics approval This study was approved by the Ethical Review Board of the School of Medicine, Keio University, and is in compliance with the Declaration of Helsinki (approval number 20170132, 01/15/2018).

Provenance and peer review Not commissioned; externally peer reviewed.

Data availability statement No data are available. The authors' agreement with the participants of the study precludes sharing of data used for this study outside the predetermined study group.

Open access This is an open access article distributed in accordance with the Creative Commons Attribution Non Commercial (CC BY-NC 4.0) license, which permits others to distribute, remix, adapt, build upon this work non-commercially, and license their derivative works on different terms, provided the original work is properly cited, appropriate credit is given, any changes made indicated, and the use is non-commercial. See: http://creativecommons.org/licenses/by-nc/4.0/.

ORCID iD

Nao Ichihara http://orcid.org/0000-0002-6902-2342

\section{REFERENCES}

1 Damiani G, Farelli V, Anselmi A, et al. Patterns of long term care in 29 European countries: evidence from an exploratory study. BMC Health Serv Res 2011;11:316.

2 Fujisawa R, Colombo F. The long-term care workforce: overview and strategies to adapt supply to a growing demand.OECD Health Working Papers No.44; 2009.

3 Care Work Foundation. Research paper of the fact of care workers in facilities and at homes (in Japanese) 平成30年度介護労働実態調査 介護労働者の就業実態と就業意識調査, 2018. Available: http://www. kaigo-center.or.jp/report/pdf/2019_chousa_roudousha_chousahyou. pdf [Accessed 1/20/2020].

4 Gospel H. Varieties of qualifications, training, and skills in longterm care: a German, Japanese, and UK comparison. Hum Resour Manage 2015.

5 Ministry of Health, Labour and Welfare. Securing nursing care workers and innovations in nursing care settings (in Japanese) 介護 人材の確保・介護現場の革新, 2019. Available: https://www.mhlw.go. jp/content/12300000/000531297.pdf [Accessed 08/20/2019].

6 Statistics Bureau of Japan. Frequently Asked Questions concerning Labour Force Survey [Internet], 2020. Available: https://www.stat.go. jp/english/data/roudou/qa-1.html

7 Squires JE, Hoben M, Linklater S, et al. Job satisfaction among care Aides in residential long-term care: a systematic review of contributing factors, both individual and organizational. Nurs Res Pract 2015;2015:1-24.

8 Buchan J, Campbell J. Challenges posed by the global crisis in the health workforce: no workforce, no health. BMJ 2013;347:1-3. [Internet].

9 Morgan SG, Willison DJ, Forest P-G, et al. New models for the new healthcare. Healthc Pap 2004;4:84.

10 Nowrouzi B, Giddens E, Gohar B, et al. The quality of work life of registered nurses in Canada and the United States: a comprehensive literature review. Int J Occup Environ Health . 2016;22:341-58. [Internet].

11 Vagharseyyedin SA, Vanaki Z, Mohammadi E. The nature nursing quality of work life: an integrative review of literature. West J Nurs Res 2011;33:786-804.

12 Chiba A. Research paper for realizing "triple aim care management" (in Japanese)「三方よし」のケアマネジメントの実現に向けた調査研 究, 2017. Available: http://cmat.jp/assets/files/170418sanpouyoshi. pdf [Accessed 12/20/2019].

13 Kemp CL, Ball MM, Jason K, et al. Contingency, employment intentions, and retention of vulnerable low-wage workers: an examination of nursing assistants in nursing homes. Gerontologist 2019;53:1-11.

14 Castle NG, Degenholtz H, Rosen J. Determinants of staff job satisfaction of caregivers in two nursing homes in Pennsylvania. BMC Health Serv Res 2006;6:60.

15 Chamberlain SA, Gruneir A, Hoben M, et al. Influence of organizational context on nursing home staff burnout: a crosssectional survey of care aides in Western Canada. Int J Nurs Stud . 2017;71:60-9. [Internet].

16 Mechanic D, Bradburn NM. The structure of psychological wellbeing. Am Sociol Rev 1970.

17 Hoorn A. a Short Introduction To Subjective Well-Being : Its Measurement, . Int Stud [Internet], 2007. Available: https://www. oecd.org/site/worldforum06/38331839.pdf

18 Lyubomirsky S, Lepper HS. A measure of subjective happiness: preliminary reliability and construct validation. Soc Indic Res 1999;46:137-55.

19 Ozkara San E. Concept analysis of nurses' happiness. Nurs Forum 2015;50:55-62.

20 Tepas DI, Barnes-Farrell JL, Bobko N, et al. The impact of night work on subjective reports of well-being: an exploratory study of health care workers from five nations. Rev Saude Publica 2004;38 Suppl:26-31.

21 Mason S, O'Keeffe C, Carter A, et al. A longitudinal study of wellbeing, confidence and competence in junior doctors and the impact of emergency medicine placements. Emerg Med J 2016;33:91-8. 
22 Tomo A, De Simone S. Exploring factors that affect the well-being of healthcare workers. IJBM 2017;12:49.

23 Poissonnet CM, Véron M. Health effects of work schedules in healthcare professions. J Clin Nurs 2000;9:13-23.

24 McVicar A. Workplace stress in nursing: a literature review. J Adv Nurs 2003;44:633-42.

25 Markwell AL, Wainer Z. The health and wellbeing of junior doctors: insights from a national survey. Med J Aust 2009;191:441-4.

26 Bishop CE, Weinberg DB, Leutz W, et al. Nursing assistants' job commitment: effect of nursing home organizational factors and impact on resident well-being. Gerontologist 2008;48 Spec No 1:36-45.

27 Kemp CL, Ball MM, Jason K, et al. Communicative Competence: Responding to Residents' Health Changes in Assisted Living. Gerontologist 2019;30:1-11.

28 Plaku-Alakbarova B, Punnett L, Gore RJ, et al. Nursing home employee and resident satisfaction and resident care outcomes. Saf Health Work 2018;9:408-15.

29 Matsuda S, Yamamoto M. Long-Term care insurance and integrated care for the aged in Japan. Int J Integr Care 2016;1:1-11.

30 Ministry of Health, Labour and Welfare. Long-Term Care Insurance System of Japan. J Digit Converg [Internet], 2016. Available: http:// www.mhlw.go.jp/english/policy/care-welfare/care-welfare-elderly/dl/ Itcisj_e.pdf

31 Tsutsui T, Muramatsu N. Care-needs certification in the long-term care insurance system of Japan. J Am Geriatr Soc 2005;53:522-7.

32 World Health Organization. Active ageing: a policy framework. Geneva, Switzerland: WHO, 2002: 5. 1-37.

33 Rubio E, Lázaro A, Sánchez-Sánchez A. Social participation and independence in activities of daily living: a cross sectional study. BMC Geriatr 2009:9:1-11.

34 Wesnes KA, Harrison JE. The evaluation of cognitive function in the dementias: methodological and regulatory considerations. Dialogues Clin Neurosci 2003;5:77-88.

35 (Zenroken) Japan Association of Geriatric Health Services Facilities. Zenroken version Elderly Care Management - R4 System - R4 System version ICF Staging 2012.

36 Okochi J, Takamuku K, Higashi K, et al. Development of a staging classification for leisure activities and social communication in dependent elderly persons. (in Japanese) 要介護高齢者における余暇 および社会交流ステージ分類の開発.. Nihon Ronen Igakkai Zasshi (日 本老年医学会雑誌) 2014:51(6):536-46.

37 Okochi J, Takahashi T, Takamuku K, et al. Staging of mobility, transfer and walking functions of elderly persons based on the codes of the International classification of functioning, disability and health. $B M C$ Geriatr 2013;13:16.

38 Okochi J, Toba K, Takahashi T, et al. Simple screening test for risk of falls in the elderly. Geriatr Gerontol Int 2006.

39 Okochi J. Data management using the ICF (in Japanese) ICFを活用 したデータマネジメント.J Clin Rehablitation 2017;26:1184-91.

40 Okochi J. Incorporating the concept of the ICF into geriatric care; development of the R4 system (in Japanese) 国際生活機能分類の理 念をいかにして施設ケアに取り込むか-「R4システム」のアセスメン 卜方式作成を通して. Japanese Journal of Public Health (日本公筫衛 生学雑誌) 2011;58(7):555-9.

41 Krueger P, Brazil K, Lohfeld L, et al. Organization specific predictors of job satisfaction: findings from a Canadian multi-site quality of work life cross-sectional survey. BMC Health Serv Res 2002;2:1-8.

42 Dill JS, Morgan JC, Marshall VW, et al. Contingency, employment intentions, and retention of vulnerable low-wage workers: an examination of nursing assistants in nursing homes. Gerontologist 2013;53:222-34.

43 von Elm E, Altman DG, Egger M, et al. The strengthening the reporting of observational studies in epidemiology (STROBE) statement: guidelines for reporting observational studies. J Clin Epidemiol 2008;61:344-9.

44 Baker B. Old age in a new age: the promise of transformative nursing homes. Old Age in a New Age: The Promise of Transformative Nursing Homes, 2007.

45 Kane RA, Lum TY, Cutler LJ, et al. Resident outcomes in small-house nursing homes: a longitudinal evaluation of the initial green house program. J Am Geriatr Soc 2007;55:832-9.

46 Shura R, Siders RA, Dannefer D. Culture change in long-term care: participatory action research and the role of the resident. Gerontologist 2011;51:212-25.

47 Mohammadi-Bolbanabad A, Shirkhani B, Mohammadi S, et al. Relationship between quality of work life of medical staff and quality of patient care. Hosp Pract Res 2016;1:61-3.

48 Castle NG, Ferguson JC. What is nursing home quality and how is it measured? Gerontologist 2010;50:426-42.

49 Miller SC, Lima JC, Thompson SA. End-Of-Life care in nursing homes with greater versus less palliative care knowledge and practice. J Palliat Med 2015;18:527-34.

50 Hooper C, Craig J, Janvrin DR, et al. Compassion satisfaction, burnout, and compassion fatigue among emergency nurses compared with nurses in other selected inpatient specialties. $J$ Emerg Nurs 2010;36:420-7.

51 Day JR, Anderson RA. Compassion fatigue: an application of the concept to informal caregivers of family members with dementia. Nurs Res Pract 2011;2011:1-10.

52 Islam MS, Baker C, Huxley P, et al. The nature, characteristics and associations of care home staff stress and wellbeing: a national survey. BMC Nurs 2017;16:22.

53 Zhang $Y$, Punnett L, Mawn B, et al. Working conditions and mental health of nursing staff in nursing homes. Issues Ment Health Nurs 2016;37:485-92.

54 Yoder EA. Compassion fatigue in nurses. Appl Nurs Res 2010;23:191-7

55 Coetzee SK, Klopper HC. Compassion fatigue within nursing practice: a concept analysis. Nurs Heal Sci 2010.

56 Mason VM, Leslie G, Clark K, et al. Compassion fatigue, moral distress, and work engagement in surgical intensive care unit trauma nurses: a pilot study. Dimens Crit Care Nurs 2014;33:215-25.

57 Cross LA. Compassion fatigue in palliative care nursing: a concept analysis. J Hosp Palliat Nurs 2019;21:21-8.

58 Melvin CS. Professional compassion fatigue: what is the true cost of nurses caring for the dying? Int J Palliat Nurs 2012;18:606-11.

59 Day JR, Anderson RA, Davis LL. Compassion fatigue in adult daughter caregivers of a parent with dementia. Issues Ment Health Nurs 2014;35:796-804.

60 Lynch SH, Lobo ML. Compassion fatigue in family caregivers: a Wilsonian concept analysis. J Adv Nurs 2012;68:2125-34.

61 Flarity K, Gentry JE, Mesnikoff N. The effectiveness of an educational program on preventing and treating compassion fatigue in emergency nurses. Adv Emerg Nurs J 2013;35:247-58.

62 Mitnitski AB, Mogilner AJ, Rockwood K. Accumulation of deficits as a proxy measure of aging. ScientificWorldJournal 2001;1:323-36.

63 Bautmans I, Lambert M, Mets T. The six-minute walk test in community dwelling elderly: influence of health status. BMC Geriatr 2004;4:6. 